\title{
Barriers to and enablers of physical activity in patients with COPD following a hospital admission: a qualitative study
}

This article was published in the following Dove Press journal:

International Journal of COPD

21 January 2014

Number of times this article has been viewed

\section{Olivia Thorpe \\ Saravana Kumar \\ Kylie Johnston}

International Centre for Allied Health Evidence, The Samson Institute for Health Research, School of Health Sciences, University of South Australia, Adelaide, SA, Australia
Correspondence: Olivia Thorpe University of South Australia, School of Health Sciences, North Terrace, Centenary Building, Adelaide, SA, Australia 5000

Tel +8 83022099

Fax +883022853

Email olivia.thorpe@unisa.edu.au
Background: Chronic obstructive pulmonary disease (COPD) is characterized by a persistent blockage of airflow, prompting episodes of shortness of breath, commonly leading to hospitalization. Hospitalization may lead to a decline in physical activity following discharge. Physical activity has been shown to improve symptoms of COPD and reduce readmissions, and to decrease morbidity and mortality. This study aims to explore, from the perspectives of people with COPD, the barriers to and enablers of participation in physical activity following hospitalization for COPD.

Methods: This study had a qualitative descriptive design and included semistructured interviews with 28 adult COPD patients who had been admitted to hospital with a primary diagnosis of exacerbation of COPD.

Results: A plethora of barriers to but fewer enablers of participation in physical activity and pulmonary rehabilitation were identified for this cohort of people. The main barriers identified were health-related (comorbidities, COPD symptoms, and physical injury or illness) environment-related (weather, transport, and finance), and self-related. The main enabling factors reported were access to health professionals and equipment, social support, routine and extracurricular activities, personal goals and motivation, and the effect of physical activity and "feeling better".

Conclusion: This research provides a snapshot of the barriers to and enablers of physical activity and pulmonary rehabilitation in people with COPD. It is evident that there are significant barriers which hinder the ability of people with COPD to undertake and continue participation in physical activity and pulmonary rehabilitation. While there are some enablers that may counter these barriers, it is clear that health professionals dealing with people suffering from COPD need to actively recognize and address barriers to physical activity and pulmonary rehabilitation. Hospital admission may create an opportunity for implementation of interventions promoting physical activity (such as referral to pulmonary rehabilitation), which may assist in reducing hospital readmission, as well as decreasing morbidity and mortality.

Keywords: chronic obstructive pulmonary disease, COPD, physical activity, exercise, hospital admission, patient perspectives

\section{Introduction}

Chronic obstructive pulmonary disease (COPD) is characterized by a persistent limitation of airflow in the lungs with the main symptom of dyspnea during exertion, often resulting in interference with work, recreation, and sleep. ${ }^{1,2}$ In Australia, COPD represents an extensive and increasing socioeconomic burden. Over two million Australians suffered with COPD in 2008, and in the same year COPD cost Australia $\$ 8.8$ billion in health care costs. ${ }^{3}$ 
The course of COPD is characterized by periodic worsening of symptoms or exacerbations requiring a change of medication, more intensive treatment, and possibly resulting in admission to hospital. ${ }^{4}$ Exacerbations are the leading cause of hospitalization in COPD patients $\mathrm{s}^{5-7}$ and represent a major health burden for patients and health care systems in both industrialized and developing countries. ${ }^{8}$ In Australia, COPD is the second leading cause of avoidable hospital admissions. ${ }^{9-11}$

It has been shown that recurrent hospitalizations lead to a decline in functional status in the elderly population. ${ }^{12}$ In the period after a hospital admission for COPD, participation in physical activity may decline compared with usual levels while people recover from a worsening of symptoms and the possible effects of inactivity during their admission. There has been very little reported on physical activity levels in people with COPD during the early recovery period post hospitalization for an acute exacerbation. This, however, has been investigated, with one study reporting that participants readmitted to hospital for an acute exacerbation had significantly lower walking time at one month when compared with patients who were not readmitted, and those who had a hospitalization for an acute exacerbation in the previous year showed less recovery in physical activity than those without hospitalization in the previous year. ${ }^{13}$

Generally, free-living participation in physical activity amongst people with COPD is low, with inactivity being associated with greater mortality and morbidity. ${ }^{14,15}$ Even in people with newly diagnosed COPD, physical activity has been shown to be lower when compared with matched controls who smoke. ${ }^{16}$ Exercise is recommended internationally in COPD management guidelines to address these issues. To date, this has been operationalized largely through the recommendation for participation of people with COPD in pulmonary rehabilitation programs. ${ }^{17-19}$

Despite the recommendations, implementation of pulmonary rehabilitation programs in people with COPD is reported to be low, with only $3 \%-16 \%$ of eligible patients being referred to pulmonary rehabilitation programs, and as few as $1 \%-2 \%$ gaining ongoing access to such programs. ${ }^{20}$ Barriers identified as hindering referral to pulmonary rehabilitation have included: limited knowledge about pulmonary rehabilitation for COPD; limited knowledge of how to refer; actual or anticipated access difficulties for patients; questioning the need to do more to promote change in exercise behavior; ${ }^{21}$ poor familiarity with the guidelines; low self-efficacy; and time constraints being significantly associated with nonadherence to referral for pulmonary rehabilitation. $^{22}$

The barriers to and facilitators of adherence to a physical activity intervention among older adults identified primary barriers such as current health problems, lack of time due to family commitments, and being employed, and primary facilitators to adherence as the health benefits attributed to the intervention and the social interaction provided by classes. ${ }^{23}$ Barriers to uptake and completion of pulmonary rehabilitation have been previously reviewed ${ }^{24}$ as well as the perspectives of barriers to and enablers of activities of daily living in a cohort of COPD patients within 2 weeks of discharge from hospital. ${ }^{25} \mathrm{~A}$ recent review by Thorpe et $\mathrm{al}^{26}$ explored barriers to and enablers of participation in physical activity and/or pulmonary rehabilitation, but identified no studies reporting on the barriers to and enablers of participation in physical activity during the crucial period following a hospital admission for exacerbation of COPD.

While barriers to participation in pulmonary rehabilitation programs have been described, little has been reported about the experience of people with COPD in relation to exercise and activity in the period after hospital admission for a disease exacerbation. Therefore, the aim of this research was to identify barriers to and enablers of participation in physical activity at 2 months after hospital admission for COPD from the perspectives of the study participants.

\section{Materials and methods Design}

A qualitative descriptive methodology was utilized to explore barriers to and enablers of participation in physical activity at 2 months after hospital admission for COPD. This naturalistic method allowed participants' views and experiences to be reported in a manner as close as possible to the data reported while presenting facts in "everyday language". ${ }^{27}$

\section{Participants}

Purposive sampling was used to recruit participants. ${ }^{28,29}$ Patients were recruited consecutively as they were admitted to the Royal Adelaide Hospital in Adelaide, South Australia, between March and November 2011. Inclusion criteria were admission to the Royal Adelaide Hospital with a documented primary complaint of exacerbation of COPD. Exclusion criteria were: inability to understand written or spoken English; inability to provide written informed consent; being younger than 18 years; or medically unstable, critically ill, or physically not well enough to participate. 


\section{Ethics}

The human research ethics committees of the University of South Australia and the Royal Adelaide Hospital approved this study. All participants gave their written informed consent prior to data collection and were reminded that they could withdraw at any stage of the research.

\section{Data collection}

Semistructured telephone interviews were used to collect data, which commenced in May 2011 and completed by January 2012, and were conducted by a single investigator (OT). Interviews were audiotaped and transcribed verbatim. A semistructured interview guide (Appendix 1) was used to ensure that the topics under investigation were covered in a consistent manner but allowing flexibility.

\section{Data analysis}

The transcripts were analyzed by the primary investigator (OT) to identify and classify categories from the data in relation to the research question. Content analysis was undertaken as the primary means of categorization of data for the purposes of classification, organization, and summarization. Content analysis is a systematic manner of describing phenomena ${ }^{30,31}$ and allows the researcher to enhance his/her understanding of the data by refining words into fewer content-related categories. ${ }^{30} \mathrm{~A}$ similar approach to content analysis has been previously reported in the literature investigating barriers to and enablers of physical activity and pulmonary rehabilitation..$^{32}$ The interview transcripts were uploaded onto a qualitative data management system (QSR NVivo version 9) where codes developed from the analysis of the interview transcripts were stored.

Recognizing the importance of trustworthiness in qualitative research, a number of key processes were put in place. These processes have been widely recommended in qualitative research literature. ${ }^{33-36} \mathrm{In}$ summary form, these strategies were: a standardized data collection protocol; interviews were audiotaped and independently transcribed verbatim; an independent observer monitored the consistency of the data collection process by sitting in on interviews at random; immersion in the data by listening to recordings and reading transcripts in their entirety; and feedback from one of the authors (SK) on coding and analyzed segments of data and emergent coding frameworks. Differences were discussed until consensus was reached; thick descriptions in the form of meaningful quotations to represent important themes and categories were included when reporting the data analysis. Participant interviews were coded until data saturation was reached, ie, no new information is gained despite ongoing data collection. ${ }^{36,37}$ The 28 semistructured interviews conducted did yield a large volume of rich data, which ultimately resulted in data saturation.

\section{Results}

\section{Description of sample}

The participant group consisted of 22 men and six women with mild $(n=2)$, moderate $(n=5)$, or severe $(n=21)$ COPD. ${ }^{18}$ Participants had a mean age of 71.86 years. On average, participants' length of stay in hospital was 6.61 days, with a minimum stay of 2 days and a maximum stay of 20 days. Within the first month after discharge from hospital, 20 participants were readmitted at least once. While the patients were in hospital, when enrollment in this study took place, pulmonary rehabilitation was discussed with eleven participants. However, only six of the eleven were actually referred for pulmonary rehabilitation, and of the six participants who were referred, only two had reported either attending or enrolling to attend a pulmonary rehabilitation program in the 2 months following hospitalization. Barriers to and enablers of participation in physical activity and pulmonary rehabilitation following a hospital admission are summarized in Figure 1.

\section{Barriers}

Participants reported a range of barriers to participating in physical activity and/or pulmonary rehabilitation following their discharge from hospital. Three main categories were identified to play important roles, namely "self", "health", and "environment". The category of "self" consisted of three subcategories, including age, physical activity or pulmonary rehabilitation, and oxygen therapy. Within the category of "health", the three subcategories included comorbidities, COPD, and physical health, and the final category of "environment" consisted of two subcategories, including participants' surroundings and transport/finance. All these factors, in combination and/or in isolation, seemed to act as barriers to participation in physical activity and/or pulmonary rehabilitation.

\section{Self}

The category of self relates to a number of important factors that participants reported as being a barrier to their participation in physical activity and pulmonary rehabilitation. Within this category, three subcategories were identified, ie, aging, lack of access to oxygen therapy, and physical activity and pulmonary rehabilitation. 


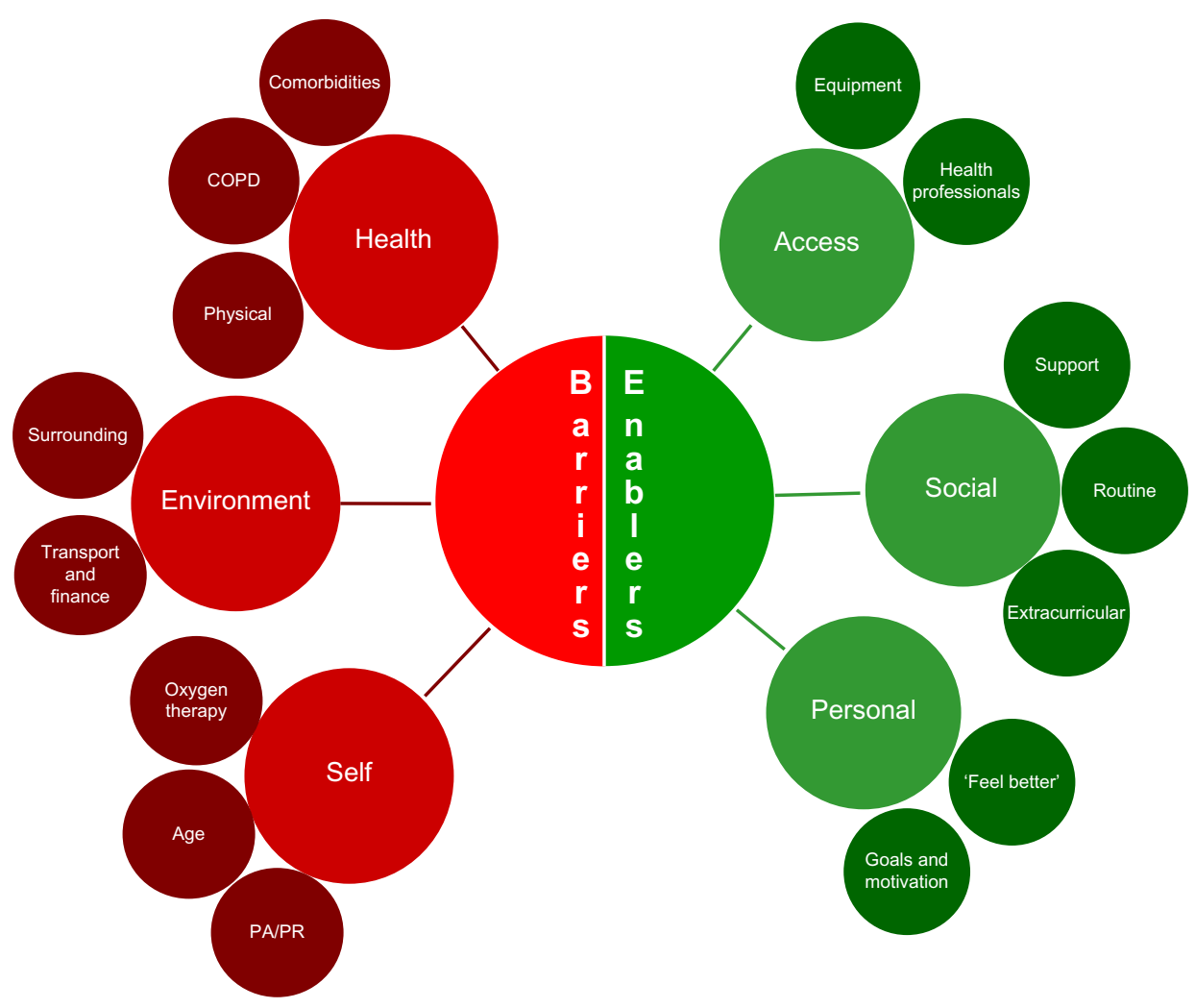

Figure I Overview of reported barriers and enablers to participation in physical activity and pulmonary rehabilitation. Abbreviations: PA, physical activity; PR, pulmonary rehabilitation; COPD, chronic obstructive pulmonary disease.

\section{Advancing age}

Participants reported that their advancing age often acted as a barrier. It was unclear if this was merely a perception of advancing age or if advancing age did negatively impact on their ability to undertake physical activity/pulmonary rehabilitation.

"I suppose the other thing is my age. I'm $71 \ldots$ my age is such that it's a limit, I guess, to what I could do and the way that anything that's required, it's difficult."

\section{Pulmonary rehabilitation/physical activity}

Pulmonary rehabilitation or physical activity was the second subcategory reported within the self category. This included negative experiences of previous programs, such as the intensity of physical activity and program centric barriers, including not being followed up regularly or having had a bad previous experience while attending pulmonary rehabilitation. The intensity of the physical activity during pulmonary rehabilitation was described by participants as requiring a "couple of days to get over it" and time to settle down to catch their breath:

"After each time I go there [pulmonary rehabilitation], it takes me a couple of days to get over it ... For me to arrange for a walk down the passage this morning, get up on the bed, and by the time I made myself comfortable it takes me half hour to settle down to catch my breath."

Intensity was a barrier indicated by another participant who encountered a previous "scary" experience of pulmonary rehabilitation. This participant recalled the after-effects of attending a session at a local health service, which led to a hospital admission. This resulted in him not wanting to return to pulmonary rehabilitation:

"I've done that on a previous occasion. I got to the [rehabilitation hospital] campus, which is fairly close to where we now live. I only attended for two or three sessions and I was admitted to hospital. This is going back probably three years. I went to hospital ... and that was scary enough. But I stay at home. I just didn't feel that I wanted to go back to [the rehabilitation hospital]. We're going through a process at the moment of looking at a whole lot of things including approaching [the rehabilitation hospital] again.”

This highlights how an intervention that is meant to assist people with COPD may in fact have the exact opposite effect. Similarly, participants reflected that lack of follow-up also negatively influenced their return to pulmonary rehabilitation. 
Despite an interest in joining, many participants reported they had not heard from organizations regarding how to access pulmonary rehabilitation. Many were unsure as to what was happening with commencement of pulmonary rehabilitation.

"Oh yes, they were going to do something about that, but they didn't. They didn't ring back ... I haven't heard anything about it at all ... The problem with all these things is that they never follow them up. If I ring them up they don't know what I'm talking about."

\section{Oxygen therapy}

Due to the nature of COPD, and the commonly associated restricted airflow experienced, oxygen therapy is prescribed for hypoxemia in people with COPD based on the results of an arterial blood gas test. There are clear guidelines to determine who is eligible for accessing home-based oxygen therapy. ${ }^{18}$ Thus, not all patients experiencing breathlessness during exertion are eligible for home oxygen. It was reported by one participant that his walking abilities increased when he was able to use oxygen therapy in hospital, but when he no longer had access to this therapy at home he "couldn't do a thing":

“Without oxygen I can't. On oxygen for half an hour I'm as good as gold for about two hours, even in here ... You can get around and walk all over the place just like that, get on the oxygen for half an hour, give it a go. They tried me one day in the week without it and I couldn't do a thing."

\section{Health}

Health was of the second of the three main barriers identified. Within this category, participant quotes were coded in subcategories of COPD, ie, comorbidity and physical. COPD was the most commonly reported health barrier and has been placed as the first of the subcategories within the category of health. The category of COPD included barriers arising from the disease itself, such as shortness of breath or a lack of oxygen and hospital admissions related to COPD. This category also included issues relating to loss of quality of life due to inability to continue with valued activities and hobbies. Shortness of breath or a lack of oxygen was the most commonly reported barrier restricting participation in physical activity. It was mentioned that if participants were sedentary (speaking on the phone or sitting at home) their breathing was sufficient; however, any exertion caused shortness of breath and they could not breathe:

"I'm alright speaking to you on the phone. I'm fine. But to get up and walk around, I'm absolutely useless at this point in time. I'm not feeling well at all. And just normally a lack of air, lack of breath. Any exertion, and I've got to sit down."

Shortness of breath not only restricted participation in pulmonary rehabilitation, but also affected activities of everyday living, such as walking.

"I still can’t walk too far. I don’t get any pain, but I just get a short of breath and that. Run out of wind ... I wouldn't be able to do it [vacuum/mop] anyway because I run out of air too quick."

This was apparent in one participant who reported getting breathless from walking down the passage way in his home:

"I bring the bottle down with me. But it doesn't take much for me to get out of breath, you know. Just walking up the passage and grabbing my oxygen bottle, it sort of makes me puff a bit."

Symptoms of COPD (ie, shortness of breath) were reported as a barrier to the participants' previous hobbies, with volunteer work, gardening, and sports listed as activities that could no longer be completed as a result of COPD.

"No, no. I used to do [light activities and muscle strength weights], but I gave it up a couple of years back. I was digging my garden, planting some vegetables, this and that. But now when I bend down I'm short of breath, I can't do it no more."

In addition to hobbies, participants also reported having to stop volunteer work due to no longer being able to because of not being able to breathe:

"No, I've had to give that away, love. I couldn't keep it up.

I used to do volunteer work, but I can't do it now."

\section{Comorbidities}

Comorbidities are a common finding in people with COPD. For the purpose of this category, comorbidity was reported if one or more unrelated diseases (or disorders) were mentioned as a barrier to participation in physical activity/pulmonary rehabilitation, in addition to COPD. For example, one participant reported that:

"I always thought it was my lungs that were doing this. But lately, as you say, it's now the heart, which I never registered it as the heart. I thought it was all lungs. So it is my heart as well as my lungs. Plus I've got CLL [chronic lymphoid leukemia] as well." 
The complexity of multiple comorbidities and their impact on participation in pulmonary rehabilitation was also highlighted by another participant.

“... I was not feel[ing] well enough to go there [pulmonary rehabilitation] ... if I'm unwell, heart condition, breathing condition, lungs, and everything else."

\section{Physical}

Issues associated with physical well-being were also commonly reported by participants. This subcategory of health encompassed any physical injury or illness experienced by the participant that restricted their ability to participate in physical activity/pulmonary rehabilitation. Within the subcategory of physical, not being well as a result of injury, sickness, and a feeling of deterioration all had an impact on their participation in physical activity/pulmonary rehabilitation. Sickness and injury often left participants feeling that they were going backwards. One participant commented contemplating going back to hospital:

"I'm starting to go backwards again, and I'm contemplating going back into the hospital ... last week I started to go downhill ... I've got a bit of a wog which is not helping. I don't think ... unfortunately I've got to tell you that I've gone backwards really ... I'm not feeling well at all."

Likewise, another participant commented that a "crook back" had caused him to be bedridden for a week:

"I've been laid up in bed with a crook back. Very severe.

I had to go to hospital for it ... and I've been laid up in bed for five days."

Many of the barriers reported to restrict participation in physical activity and pulmonary rehabilitation are complex, and interrelated with many different factors affecting the participants' ability to be active. One participant with physical issues (including his lung condition, a "dodgy back", capillary problems in his legs, pneumonia, and stomach issues) described himself as:

"Not only have I got emphysema ... I'm just generally falling apart."

\section{Environment}

The category of environment was divided into two main subcategories, ie, surroundings and transport/finance.

\section{Surroundings}

Within this subcategory, there were different "environmental" factors that contributed to participants being restricted in participating in physical activity/pulmonary rehabilitation. The weather was described as an environmental barrier affecting participation in physical activity/pulmonary rehabilitation, with seasonal weather patterns perceived to affect health and reduce the ability to spend time outside.

"If it gets too cold, I won't go out at all. Or if it's too humid in the warmer weather."

It was also mentioned by participants that the cold weather was the cause of pneumonia and hospital admission:

"... The cold weather does affect my mobility and my tendency

to have periods where my wife has to take me to hospital."

"The weather makes me sneeze and cough a lot and when the winter comes in I have at least three bouts of pneumonia, well I did this year."

The weather was also mentioned as having a detrimental effect on breathing, with many participants reporting that cold weather or "cold air" made it difficult to breathe, or was the cause of shortness of breath.

“... It's not so bad in the warm weather, but you get the warm weather, you know, I just can't go outside much. Because you can't breathe in all that cold air, it sort of bungs your lungs up a bit I think."

Other environmental factors identified as limiting participation in activity were pollen and dust. Some participants reported that the dust associated with their hobbies, eg, woodwork, either caused them to give it up or be very careful not to trigger an exacerbation.

"I do a bit of woodwork here at home, just sort of hobby stuff. I've got a few things that I just mess around with, and I have to be really careful with anything that produces dust or anything like that, because obviously that gives me a problem with breathing, or can do."

\section{Transport and finance}

Transport and parking difficulties were described by participants as a "major barrier", especially when attending pulmonary rehabilitation. Closely linked with transport was the financial burden of paying for parking or transport via a taxi service. Within this category, the ability to afford costly portable oxygen equipment was a reported barrier, and one participant expressed having difficulty carrying the standard oxygen equipment. This participant also reported that transport was a major barrier to getting about:

"... the availability of transport is the major barrier." 
The same participant reported that he had to give up his driver's license due to the difficulty he had getting out and filling the car with petrol, which limited his transport to when his spouse was available:

"I could drive okay, but when I got to somewhere, to get out and go and pay for petrol was very difficult because of the breathing ... so my movement outside the house is limited to when the family car is available and [wife] is driving."

Conversely, another participant stated that although transport as such was not a problem in getting to pulmonary rehabilitation, the cost of parking or getting a taxi made it unaffordable:

"I go to [pulmonary rehabilitation location], and I have to pay a parking fee there, I'm disabled, I cannot pay it ... It's impossible ... I've got to get a taxi, it costs me \$20, I can't afford $\$ 20$ on the pension."

The same participant described the burden of carrying around his oxygen equipment, which was stopping him from participating in activities of daily living because he was not in a financial position to be able to afford a portable oxygen machine.

"I mean, I would love to do (Activities of Daily Living [ADL] such as housework), but I've got to carry my battery with the oxygen, because the government doesn't give you that - it's a beautiful battery you can carry ... but I have to buy it myself, it would cost me $\$ 6,000$ and I can’t afford it.”

\section{Enablers}

Participants reported many factors which enabled their participation in physical activity and/or pulmonary rehabilitation. Three main factors were identified as being enabling influences and these have been categorized as social, personal, and access.

\section{Social enablers}

The category of social relates to a number of important factors that participants reported as being enablers to their participation in physical activity and pulmonary rehabilitation. Within this category, three distinct subcategories were identified, namely support, routine, and extracurricular activities.

\section{Support}

Having a chronic disease, such as COPD, can be debilitating, with the coping and ongoing management of the condition requiring regular support from family and friends.
Having a social outlet involving contact with and participation by family and friends may act as a facilitator for getting out of the house and into social events. It was reflected that "getting older" meant there were opportunities for families to get together and visit each other's homes. This provided the opportunity to undertake physical activity in a new environment.

"I'm going with my brother for a couple of days ... We're all getting older, so we've got to visit one another now and again ... [his family member] has got a bit of a farm and we walk around the countryside down there. I've also got a brother who lives up at Heathfield. I was up there last Thursday walking around his countryside."

In addition to special events, such as family visits, many participants reflected that activities of everyday living and social engagements interspersed within these activities were also opportunities for physical activity. One participant observed that:

"We would at times, if we go to visit friends and members of the family and those shopping exhibitions, we seem to go if we have the money."

Another participant reported on the potentially untapped role of family members as enablers of physical activity and pulmonary rehabilitation for COPD patients, reporting that his grandson had recommended the use of a treadmill as a means of undertaking physical activity:

\footnotetext{
"He [grandson] comes over and gets on the treadmill ... He reckons it's better to walk in the warmth than it is out and freeze ... see, I've got my great grandson here. Son-in-law. But he's starting to do the weights, starting to buy them. And I'll start using them."
}

\section{Routine}

It could be assumed that the routine of everyday life could be disrupted following hospital admission, and that this would hinder the normality of everyday life. However, we found that this was not the case. Participants in our research reported that regaining their routine was an enabler after their hospital admission, and that activities of daily living provided them with opportunities to partake in physical activity. Shopping and undertaking errands were commonly reported by participants as part of their routine activities of daily living.

"Every day. Nearly every day. But most of the time when I need to buy some tucker, some food, you know? And I have to go down to the shops to buy it." 
Some participants reported that having this routine was the only physical activity that they currently partake in:

"All I do is go to post office not far from us, around the corner so to speak, where I pay the bills. That's the only walking I do."

Participants commonly reported that walking was integral to their everyday routine, with many recounting walking within the previous week.

"I've just walked from Victoria Square, which is about half a mile ... I'm out nearly every day walking. I go for a walk at least a quarter, or half a mile."

Similarly, one participant reported that weights were an essential part of his routine, and that he did his repetitions while watching television:

"Night time I sit and watch TV, and I've got 10 pound weights, and I do 20 lift ups with each arm. Twenty, 20, 20, 20 , you know. And that keeps my upper body a little bit. I've been doing that for the last 10, 15 years. It keeps my upper body strength a little bit better than not doing anything."

\section{Extracurricular activities}

Extracurricular activities, such as hobbies, are a common facet of people's lives. This was acknowledged by one participant who stated that his hobby was the closest he came to a sporting activity, and that it allowed some exercise from a wheelchair:

"I do a bit of woodwork here at home, just sort of hobby stuff. I've got a few things that I just mess around with ...

I'm [also] a member of a club which is composed mainly of older men who can no longer afford or are no longer fit enough to sail. So we have small miniature yachts which are radio controlled ... and [we are] trying to beat each other at certain distances. And I guess that's the closest I come to a sporting activity, but it is in the open air and it does require some exercise in the wheelchair."

This highlights the opportunities available for people with COPD to undertake physical activity. Without such opportunities, people with COPD may have very limited access to physical activity.

\section{Personal enablers}

This category relates to any personal (individual-centric) factors reported to act as enablers and facilitate involvement in physical activity or pulmonary rehabilitation. The personal enablers reported here have been subcategorized into "feeling better" and goals and motivation.

\section{Feeling better}

In this subcategory, the positive outcomes gained have been reported as enablers for continuing to undertake and participate in physical activity/pulmonary rehabilitation. Participants reported feeling fit, better, and having better breathing outcomes after participating in physical activity and pulmonary rehabilitation.

“... I have to exercise. Which I would do every day. And

I feel a lot better, you know, my legs are a lot better. But once I get on the exercise bike, well that helps you to walk a bit further. It's only natural, isn't it?"

Another participant reported feeling better and experiencing improved breathing after attending pulmonary rehabilitation.

"Well when you go there [pulmonary rehabilitation] and you do a lot of things, you know, bike, and weights, and things like that, for at least a couple of days you put everything off your mind, you know you can do something. And I feel much better when I go there ... I can breathe better."

\section{Goals and motivation}

Goal-setting is a well known technique for achieving goals, and is a successful and powerful motivator. Participants reported that physical activity was a method of achieving the goals they had set for themselves. Self-motivation was also described as a personal factor facilitating participation in physical activity. Motivation can arise from a number of sources, including ability to play with grandchildren, weight maintenance goals, and preparing for upcoming events. This was described by one participant wanting to maintain his fitness because he was giving away the bride at a wedding:

“But I've got to get myself right because I've got a wedding to go to on the 29th ... And I've got to give the bride away ... Yes, I've got to try and get myself up to that fitness, so that I can keep going."

This was similarly described by another participant who wanted to get "fairly fit" in preparation for a fishing trip:

"I'll be going fishing in a month's time for about 12 days, and I want to get fairly fit for that. So I have to exercise."

\section{Access enablers}

The access category includes the opportunity for people with COPD to have access to a range of resources that are instrumental in their participation in physical activity and pulmonary rehabilitation. In particular, access to equipment and to health 
professionals were reported as factors enabling participation in physical activity and pulmonary rehabilitation.

\section{Access to equipment}

Having access to equipment was an enabler reported to aid participation in physical activity and pulmonary rehabilitation. Conversely, not having access to equipment such as oxygen apparatus was a commonly reported barrier. One participant reported being aid-free, except for carrying oxygen and occasionally a wheelchair which allowed them to get out of the house:

"I quite often sort of manage to get up into a house without any aids, except carrying an oxygen bottle. And that works out fairly well for me ... if I do go out, it's usually in the car and carrying oxygen with me ... Most of the time I am supported by my oxygen in one way or another, and the wheelchair as well."

\section{Access to health professionals}

Having access to health professionals was an important enabler, with their help and advice reported as being of great benefit to people with COPD. Participants commented that advice regarding exercise intensity, coughing up sputum, breathing, and exercises was particularly welcome. One participant was given advice on how to cough up phlegm properly, which he had previously had trouble doing successfully:

“There was a chap there [pulmonary rehabilitation], he's a physiotherapist. And he just gave me a couple of treatments, you know, on the lungs and that. How to cough up and all that. Well, he helped me a hell of a lot, you know, on what to do and what not to do."

Another participant recounted being taught how to "open the airways" to assist breathing correctly:

"He told me a few things, how to breath. Before I use the oxygen I've got to open the airways with puffers and things."

Due to the nature of COPD, targeted assistance is sometimes required because generic exercises may not be appropriate in specific individuals. Having access to health professionals therefore gave participants an opportunity to discuss their problems and seek advice. One participant reported suggestions he had been given regarding how to modify exercises, which helped him feel better:

"Physiotherapists have suggested things such as sort of leaning down on a desk, and exercising my back, and some of my stomach muscles with doing more or less pushups, but doing them in a way that's quite painless and doesn't really do very much. But it does make you feel a little bit better to do that sort of thing. I have done a bit of that."

Positive reinforcement and advice provided by the consulting doctor was a strong enabler. Despite their difficulties, participants seemed to value professional advice and had intentions of putting it into practice. One participant commented:

"Dr [X] says that I must try and walk, do away with my gopher, without the gopher, a couple of times a week to go 200 meters up to the lunch room to walk ... because he said to try and make your lungs work harder. But there's been this bloody awful weather. It's easier to get on the gopher than struggle up against the cold wind and trying to make myself puff. I will get around to it, I hope.”

\section{Discussion}

This is the first Australian study to focus on the patient perspective concerning the impact of hospitalization on participation in physical activity in a cohort of people with COPD. The only other study identified with a similar focus was undertaken in Taiwan by Jeng et al, ${ }^{25}$ which explored the experiences of daily activities in elderly people with COPD within 2 weeks of discharge from hospital and explored their perspectives of barriers to and enablers of activities of daily living. Patient experiences in the current study were similar to those reported by Jeng et $\mathrm{al}^{25}$ with regard to "external" factors, such as weather and transport. Additionally, participants in the study by Jeng et $\mathrm{al}^{25}$ reported the fear associated with exacerbation of symptoms and having to "slow and simplify" their activities and perform within their limitations in order to "protect themselves". Another unique feature of the current research was the population of interest. The participants had severe COPD, and had presented to hospital for management of worsening of their symptoms. Therefore, this research focused on people with COPD who required hospitalization and represent the sector of the COPD population with the highest health care costs. ${ }^{3}$

The findings of our study add to the emerging body of evidence regarding barriers to uptake and completion of physical activity and pulmonary rehabilitation in people with COPD. ${ }^{25,38-47}$ This study also provides new knowledge regarding patient perceptions of enabling factors that help them to participate in physical activity, including pulmonary rehabilitation. The identified enablers provide new insight into the role of beliefs about the benefits of 
exercise, support of family and health professionals, and the ways people with COPD were able to integrate activity into their daily lives.

There are a number of barriers that confront COPD patients when they participate in physical activity and pulmonary rehabilitation post hospitalization. These barriers are not limited to one type or context, and extend to individual, physical, organizational, and environmental factors. The complexities underpinning these barriers reflect the complexity associated with holistic management of COPD, and promoting physical activity and pulmonary rehabilitation specifically.

Poor health was the most commonly reported barrier, with COPD-related symptoms such as shortness of breath, comorbidities, illness and physical health, affecting the participants' ability to participate in physical activity/ pulmonary rehabilitation. This study explored the barriers to and enablers of physical activity and pulmonary rehabilitation in people with COPD following an exacerbation of symptoms requiring a hospital admission. Given that participants were recruited following an exacerbation of symptoms, it is not surprising that poor health was the main barrier in this cohort. On the other hand, in research examining people with "stable" COPD (ie, not following an exacerbation of symptoms or requiring hospital admission), the main barriers reported were related to transport, a lack of perceived benefit, and being unwell. ${ }^{44}$ Further, previous studies in "stable" population groups showed that an exacerbation or worsening of COPD symptoms was the primary reason for dropping out of a pulmonary rehabilitation program. ${ }^{41,42}$ Studies have also reported that fear and anxiety surrounding re-exacerbation restricts participation in physical activity and pulmonary rehabilitation. ${ }^{39-41,43,45}$ Participants in this study had recently experienced an exacerbation of symptoms requiring hospital admission, which may have been fresh in their minds, causing anxiety regarding re-exacerbation of symptoms. As encompassed under poor health, comorbid conditions were commonly reported as a barrier to participating in physical activity and pulmonary rehabilitation. Although COPD patients often have one or more comorbidities, no information is available on the prescription parameters for exercise training in patients with multimorbidity. ${ }^{48}$

Other key barriers to physical activity and pulmonary rehabilitation identified in the current study concur with those previously reported, including "external" factors such as transport, parking, and other environmental factors, ${ }^{25,38,41,45-47}$ changing health status, ${ }^{38-47}$ and program-specific barriers, such as the intensity, ${ }^{40,43}$ referring medical practitioner, ${ }^{38}$ lack of progress, ${ }^{40}$ and length of the program. ${ }^{47}$

While a plethora of barriers were reported, some enabling factors were also reported as a means of addressing these barriers; however, these were often outnumbered by the barriers. An important link between the barriers and enablers was access to equipment with report of this being both a major barrier and an enabler. Interestingly, enablers seemed to cluster around the needs of the individual with COPD (such as social support and interaction, personal beliefs, goals and motivations, and access) where barriers were widely diverse. Similar findings were reported in a study by Lewis and Cramp, ${ }^{45}$ who found many enabling strategies which focused on the needs of individuals with COPD and proposed ways to improve participation by addressing them specifically, for example, providing variation in the program classes and having company. Similarly, a recent review of the barriers of and enablers to participating in physical activity for people with COPD reported that enabling factors, such as personal drivers and personal attributes/benefit, were cited in all included studies. ${ }^{26}$

While achieving behavioral change is complex, a critical factor in achieving success change is the identification of barriers, and addressing these through targeted enabling strategies. ${ }^{49}$ In a study of patients recently discharged from hospital after an acute exacerbation of COPD, it was reported that personalized self-management advice, better education on the use of oxygen, and increased use of combination therapies, including pulmonary rehabilitation, were required. ${ }^{50}$ Therefore, promoting participation in physical activity and pulmonary rehabilitation among people with COPD may be achieved by developing targeted enabling strategies for COPD patients, which recognize their individual needs and address the barriers identified in this study, including access and linkages to ways to stay active, and strategies to cope with worsening of symptoms and comorbid conditions. Chavannes et $\mathrm{al}^{51}$ reported successful initiatives in a population of people with COPD, such as the implementation of personalized physical activity training programs, through the use of a management team and Kruis ${ }^{52}$ successfully implemented integrated care in "real life" COPD populations.

\section{Limitations}

This study included a slightly older aged group of mostly males (79\%) with severe COPD (75\%) admitted to a public hospital in Adelaide, South Australia. This limits the generalizability of the study findings. Another limitation is the exclusion of non-English-speaking people, and as such, 
excludes some of the cultural and ethnic groups found in the wider community. This raises the possibility of the nonEnglish speaking community experiencing different barriers to or enablers of participation in pulmonary rehabilitation and physical activity after hospitalization.

\section{Implications for practice}

The findings of this study provide a snapshot of the complex array of barriers that people with COPD face when engaging in physical activity. It is important that health professionals are cognizant of these barriers when recommending physical activity for people with COPD. These barriers need to be explicitly acknowledged and suitably addressed because, without due diligence, they are likely to result in poor uptake of physical activity. Recognizing these factors provides a timely opportunity for health professionals to use both the barriers people experience and the enabling strategies that encourage physical activity when developing tailored programs that promote enabling strategies for individual barriers. The findings of this study also indicate that there is no "one size fits all" approach, which is an important consideration and underscores the importance of an individualized and targeted approach. Therefore, although common barriers to and enablers of participation in physical activity have been reported in this cohort, it is essential for health professionals to partner with patients to individualize strategies to implement and sustain participation in physical activity in such patients.

\section{Implications for research}

Our findings provide a unique perspective of barriers and enablers from the point of view of people with COPD. While a number of barriers were identified, few enablers are available to counter these barriers. Further research into the effectiveness of enabling strategies (which are matched with specific barriers) for participation in physical activity in this population, with assessment of long-term outcomes and sustainability, is required. This approach is important due to the complex and wide-ranging impact of barriers to participation in physical activity and pulmonary rehabilitation in people with COPD. By implementing and evaluating targeted enabling strategies, new knowledge can be created in terms of what strategy works for whom, when, why, and how. This research also sheds light on the minimal "conversations" that exist between people with COPD and health professionals regarding pulmonary rehabilitation. Despite the strong evidence for the important role of pulmonary rehabilitation in people with COPD, less than half of the participants in this study were referred to pulmonary rehabilitation, with significant attrition among those who commenced a pulmonary rehabilitation program. Future research could explore the communication gap between people with COPD and health professionals regarding pulmonary rehabilitation and the lack of consistent referral and uptake.

\section{Conclusion}

The current research has provided a comprehensive picture of self-reported barriers and enablers for physical activity and pulmonary rehabilitation in people with COPD around the crucial time of hospitalization for an exacerbation of their COPD symptoms. Based on these findings, it is evident that there are significant barriers which hinder the ability of people with COPD to undertake and continue to participate in physical activity and pulmonary rehabilitation. These include social, personal, and disease-related issues, highlighting the complexities associated with addressing these barriers and promoting active engagement in physical activity and pulmonary rehabilitation. While there are some enablers which may be utilized in addressing some of these barriers, it is clear that health professionals dealing with patients suffering from COPD, especially those with severe COPD, need to actively recognize and address barriers to physical activity and pulmonary rehabilitation. Without such explicit recognition and action, people with COPD may succumb to these barriers and may never be able to actively undertake and participate in physical activity and pulmonary rehabilitation, despite the fact that they desperately need it. Hospital admission in this population could create an opportunity for implementation of interventions that promote physical activity (such as referral to pulmonary rehabilitation), which may assist in reducing hospital readmission, and morbidity and mortality.

\section{Disclosure}

The authors report no conflicts of interest in this work.

\section{References}

1. Frith PA, Cafarella PA, Duffy JM. Chronic obstructive pulmonary disease (COPD) is a major personal and public health burden in Australia. Aust N Z J Public Health. 2008;32:139-141.

2. World Health Organization. Chronic obstructive pulmonary disease (COPD). 2013; Available from: http://www.who.int/mediacentre/ factsheets/fs315/en/. Accessed November 13, 2013.

3. Access Economics. Economic Impact of COPD and Cost-Effective Solutions. Canberra, Australia: The Australian Lung Foundation; 2008.

4. Wesseling G, Vrijhoef HJ. Acute exacerbations of COPD: recommendations for integrated care. Expert Rev Respir Med. 2008;2:489-494.

5. Lodewijckx C, Sermeus W, Vanhaecht K, et al. Inhospital management of COPD exacerbations: a systematic review of the literature with regard to adherence to international guidelines. J Eval Clin Pract. 2009;15: $1101-1110$. 
6. Lusuardi M, Blasi F, Terzano C, et al. Standards of care and clinical predictors in patients hospitalised for a COPD exacerbation - the Italian SOS (Stratification Observational Study). Monaldi Arch Chest Dis. 2009;71:153-160.

7. Sutherland E, Cherniack R. Management of chronic obstructive pulmonary disease. $N$ Engl J Med. 2004;350:2689-2697.

8. Toy EL, Gallagher KF, Stanley EL, Swensen AR, Duh MS. The economic impact of exacerbations of chronic obstructive pulmonary disease and exacerbation definition: a review. COPD. 2010;7:214-228.

9. Ansari Z, Haider SI, Ansari H, de Gooyer T, Sindall C. Patient characteristics associated with hospitalisations for ambulatory care sensitive conditions in Victoria, Australia. BMC Health Serv Res. 2012;12:475.

10. Katterl R, Anikeeva O, Butler C, Brown L, Smith B, Bywood P. Potentially Avoidable Hospitalisations in Australia: Causes for Hospitalisations and Primary Health Care Interventions. Adelaide, Australia: Primary Health Care Research and Information Service; 2012.

11. Page A, Ambrose S, Glover J, Hetzel D. Atlas of Avoidable Hospitalisations in Australia: Ambulatory Care-Sensitive Conditions. Adelaide, Australia: Public Health Information Development Unit, University of Adelaide; 2007.

12. Inouye SK, Wagner DR, Acampora D, Horwitz RI, Cooney LM Jr, Tinetii ME. A controlled trial of a nursing-centered intervention in hospitalized elderly medical patients: the Yale Geriatric Care Program. J Am Geriatr Soc. 1993;41:1209-1211.

13. Pitta F, Troosters T, Probst VS, Spruit MA, Decramer M, Gosselink R. Physical activity and hospitalization for exacerbation of COPD. Chest. 2006; 129:536-544.

14. Garcia-Aymerich J, Lange P, Benet M, Schnohr P, Anto JM. Regular physical activity reduces hospital admission and mortality in chronic obstructive pulmonary disease: a population based cohort study. Thorax. 2006;61:772-778.

15. Waschki B, Kirsten A, Holz O, et al. Physical activity is the strongest predictor of all-cause mortality in patients with COPD: a prospective cohort study. Chest. 2011;140:331-342.

16. Van Remoortel H, Hornikx M, Demeyer H, et al. Daily physical activity in subjects with newly diagnosed COPD. Thorax. 2013;68:962-963.

17. Global Initiative for Chronic Obstructive Lung Disease. Global strategy for the diagnosis, management, and prevention of chronic obstructive pulmonary disease. 2010. Available from: http://www.goldcopd. org/uploads/users/files/GOLDReport_April112011.pdf. Accessed November 13, 2013.

18. McKenzie D, Abramson M, Crockett A, et al. The COPD-X Plan: Australian and New Zealand Guidelines for the Management of Chronic Obstructive Pulmonary Disease 2010. Milton, Australia: The Australian Lung Foundation; 2010.

19. The National Collaborating Centre for Chronic Conditions. Chronic obstructive pulmonary disease. National clinical guideline on management of chronic obstructive pulmonary disease in adults in primary and secondary care. Managing stable COPD. Thorax. 2004;59: i39-i130.

20. Johnston K, Grimmer-Somers K. Pulmonary rehabilitation: overwhelming evidence but lost in translation? Physiother Can. 2010;62:368-373.

21. Johnston KN, Young M, Grimmer KA, Antic R, Frith PA. Barriers to, and facilitators for, referral to pulmonary rehabilitation in COPD patients from the perspective of Australian general practitioners: a qualitative study. Prim Care Respir J. 2013;22:319-324.

22. Perez X, Wisnivesky JP, Lurslurchachai L, Kleinman LC, Kronish IM. Barriers to adherence to COPD guidelines among primary care providers. Respir Med. 2012;106:374-381.

23. Garmendia ML, Dangour AD, Albala C, Eguiguren P, Allen E, Uauy R. Adherence to a physical activity intervention among older adults in a post-transitional middle income country: a quantitative and qualitative analysis. J Nutr Health Aging. 2013;17:466-471.

24. Keating A, Lee A, Holland AE. What prevents people with chronic obstructive pulmonary disease from attending pulmonary rehabilitation? A systematic review. Chron Respir Dis. 2011;8:89-99.
25. Jeng C, Tsao LI, Ho CH, Chang PC. Experiences of daily activities within two weeks after hospital discharge among Taiwanese elderly patients with chronic obstructive pulmonary disease. J Nurs Res. 2002;10:168-176.

26. Thorpe OP, Johnston KN, Kumar S. Barriers and enablers to physical activity participation in patients with COPD. $J$ Cardiopulm Rehabil Prev. 2012;32:359-369.

27. Sandelowski M. Focus on research methods: whatever happened to qualitative description? Res Nurs Health. 2000;23:334-340.

28. Creswell J, Plano Clark V, editors. Designing and Conducting Mixed Methods Research. 2nd ed: Thousand Oaks, CA, USA: Sage Publications Inc; 2011.

29. Ritchie J, Lewis J, Elam G. Designing and selecting samples. In: Ritchie J, Lewis J, editors. Qualitative Research Practice. London, UK: Sage Publications Inc; 2003.

30. Elo $\mathrm{S}$, Kyngas $\mathrm{H}$. The qualitative content analysis process. $J A d v$ Nurs. 2008;62:107-115

31. Krippendorff K. Content Analysis: An Introduction to its Methodology. Beverly Hills, MA, USA: Sage Publications Inc; 1980.

32. Johnston K, Young M, Grimmer-Somers K, Antic R, Frith P. Why are some evidence-based care recommendations in chronic obstructive pulmonary disease better implemented than others? Perspectives of medical practitioners. Int J Chron Obstruct Pulmon Dis. 2011;11:659-667.

33. Rice P, Ezzy D. Qualitative Research Methods: A Health Focus. Oxford, UK: Oxford University Press; 1999.

34. Barbour R. Education and debate: checklists for improving rigour in qualitative research: a case of the tail wagging the dog? BMJ. 2001;322: $1115-1117$.

35. Mays N, Pope C. Qualitative research in health care: assessing quality in qualitative research. BMJ. 2000;320:50-52.

36. Mellion L, Tovin MM. Grounded theory: a qualitative research methodology for physical therapy. Physiother Theory Pract. 2002;18: 109-120.

37. Cutcliffe J. Methodological issues in grounded theory. $J$ Adv Nurs. 2000;31:1476-1484.

38. Arnold E, Bruton A, Ellis-Hill C. Adherence to pulmonary rehabilitation: A qualitative study. Respir Med. 2006;100:1716-1723.

39. Bulley C, Donaghy M, Howden S, Salisbury L, Whiteford S, Mackay E. A prospective qualitative exploration of views about attending pulmonary rehabilitation. Physiother Res Int. 2009;14:181-192.

40. Fischer MJ, Scharloo M, Abbink JJ, et al. Participation and drop-out in pulmonary rehabilitation: a qualitative analysis of the patient's perspective. Clin Rehabil. 2007;21:212-221.

41. Fischer MJ, Scharloo M, Abbink JJ, et al. Drop-out and attendance in pulmonary rehabilitation: the role of clinical and psychosocial variables. Respir Med. 2009;103:1564-1571.

42. Garrod R, Marshall J, Barley E, Jones PW. Predictors of success and failure in pulmonary rehabilitation. Eur Respir J. 2006;27:788-794.

43. Harris D, Hayter M, Allender S. Improving the uptake of pulmonary rehabilitation in patients with COPD: qualitative study of experiences and attitudes. Br J Gen Pract. 2008;58:703-710.

44. Keating A, Lee AL, Holland AE. Lack of perceived benefit and inadequate transport influence uptake and completion of pulmonary rehabilitation in people with chronic obstructive pulmonary disease: a qualitative study. $J$ Physiother. 2011;57:183-190.

45. Lewis RC, Cramp F. Facilitators and barriers to exercise maintenance in chronic obstructive pulmonary disease: patient views. Physiotherapy Ireland. 2010;31:19-24.

46. O'Shea SD, Taylor NF, Paratz JD. ... But watch out for the weather: factors affecting adherence to progressive resistance exercise for persons with COPD. J Cardiopulm Rehabil Prev. 2007;27:166-174.

47. Sabit R, Griffiths TL, Watkins AJ, et al. Predictors of poor attendance at an outpatient pulmonary rehabilitation programme. Respir Med. 2008;102:819-824.

48. Reid W, Yamabayashi C, Goodridge D, et al. Exercise prescription for hospitalized people with chronic obstructive pulmonary disease and comorbidities: a synthesis of systematic reviews. Int J Chron Obstruct Pulmon Dis. 2012;7:297-320. 
49. Grol R, Wensing M, Eccles M. Improving Patient Care: The Implementation of Change in Clinical Practice. 1st ed. Edinburgh, UK: Elsevier; 2005.

50. Gruffydd-Jones K, Langley-Johnson C, Dyer C, Badlan K, Ward S. What are the needs of patients following discharge from hospital after an acute exacerbation of chronic obstructive pulmonary disease (COPD)? Prim Care Respir J. 2007;16:363-368.
51. Chavannes NH, Grijsen M, van den Akker M, et al. Integrated disease management improves one-year quality of life in primary care COPD patients: a controlled clinical trial. Prim Care Respir J. 2009; 18:171-176.

52. Kruis AL, van Adrichem J, Erkelens MR, et al. Sustained effects of integrated COPD management on health status and exercise capacity in primary care patients. Int J Chron Obstruct Pulmon Dis. 2010;5:407-413. 


\section{Appendix}

Appendix I Overview of semistructured interview guide: patients at 2-month follow-up

\section{Disease course}

How are things generally with your lungs now that you are home from hospital?

Have you had any episodes since you've been home where your chest or breathing got worse?

? needed to change your medication (antibiotics or prednisolone)

Have you been to see your GP or a doctor at the hospital since you came out of hospital?

Have you seen other health professionals since you got home from hospital (eg, nurse, physiotherapy, community respiratory service)

Location of visit: home, clinic?

Do you have an appointment made for a visit with a health professional in the future?

\section{Activity participation}

How are you going with your walking/daily activities/coping with breathlessness/eating since you got out of hospital? (refer to issues from hospital admission)

Physical Activity Scale in the Elderly (PASE) questions

Follow the lead from responses when in hospital

If HAS been referred to/commenced pulmonary rehabilitation while in hospital, or sometime since

When referred?

When started/anticipated starting date

How are you going to get there/back?

What sort of things made it easier for you to decide to go to pulmonary rehabilitation?

What are the best things/worst things about the program?

What gets in the way of you going to pulmonary rehabilitation?

If NOT referred in hospital:

Has anyone spoken with you about joining pulmonary rehabilitation/exercise/healthy eating/coping with your lung condition since you got home?

(eg, local doctor, liaison service from hospital, community respiratory service)

\section{Current barriers to participation in physical activity}

Are there things which are making it difficult for you to be active/do exercise in the last week?

(eg, exacerbation, comorbidity, confidence in ability to participate).

\section{Current facilitators of participation in physical activity/exercise}

What helps you keep active?

Or

Are there things which help you keep up being active?

(eg, perceived importance, enjoyment, social factors).

Psychological domains for benefits/barriers

Knowledge/awareness

Belief about capabilities

Belief about consequences/attitude

Environmental context and resources

Motivation and goals/intention

Social influences

Memory, attention, and decision-making

Emotion

Behavioral regulation

Nature of behavior

International Journal of COPD

\section{Publish your work in this journal}

The International Journal of COPD is an international, peer-reviewed journal of therapeutics and pharmacology focusing on concise rapid reporting of clinical studies and reviews in COPD. Special focus is given to the pathophysiological processes underlying the disease, intervention programs, patient focused education, and self management protocols.

\section{Dovepress}

This journal is indexed on PubMed Central, MedLine and CAS. The manuscript management system is completely online and includes a very quick and fair peer-review system, which is all easy to use. Visit http://www.dovepress.com/testimonials.php to read real quotes from published authors. 